\title{
KINERJA KONTEKSTUAL DAN FAKTOR-FAKTOR YANG MEMENGARUHI
}

\author{
CONTEXTUAL PERFORMANCE AND INFLUENCING FACTORS
}

\author{
Oleh: \\ Rion Nofrianda ${ }^{1}$ \\ Erita Yuliasesti Diah Sari ${ }^{2}$ \\ Herlina Siwi Widiana ${ }^{3}$
}

\section{Submitted: \\ 16 Desember 2019 \\ Revision: \\ 07 Januari 2020}

Accepted:

08 Januari 2020

\begin{abstract}
This study aims to examine affective commitment as a moderator on the impact of cultural orientation and job satisfaction on contextual performance. 100 employees offood outlets participated in this research. Job satisfaction scale, organizational culture scale, affective commitment scale and contextual performance scale were used to collect the data. Partial Least Square-Structural Equation Modeling (PLSSEM) was used to analysed. The results show affective commitment was not able to moderate the influence of culture on contextual performance, but affective commitment significantly influenced the impact of job satisfaction on contextual performance. Thereforeto improve contextual performance among employee, organizations may support employees to internalize organizational culture, increase high job satisfaction and encourage employees to have an affective commitment to their organization.
\end{abstract}

Keywords: Affective Commitment; Contextual Performance; Job Satisfaction; Organizational Culture.

\section{ABSTRACT}

This study aims to examine affective commitment as a moderator on the impact of cultural orientation and job satisfaction on contextual performance. 100 employees offood outlets participated in this research. Job satisfaction scale, organizational culture scale, affective commitment scale and contextual performance scale were used to collect the data. Partial Least Square-Structural Equation Modeling (PLS-SEM) was used to analysed. The results show affective commitment was not able to moderate the influence of culture on contextual performance, but affective commitment significantly influenced the impact of job satisfaction on contextual performance. Thereforeto improve contextual performance among employee, organizations may support employees to internalize organizational culture, increase high job satisfaction and encourage employees to have an affective commitment to their organization.

Keywords: Affective Commitment; Contextual Performance; Job Satisfaction; Organizational Culture

\section{PENDAHULUAN}

Dunia industri terus menerus mengalami perkembangan dengan munculnya perusahaan-perusahaan untuk memenuhi kebutuhan customer dari segala aspek kebutuhan primer maupun kebutuhan sekunder. Keberadaan pegawai sebagai Sumber Daya Manusia dapat membantu keberlangsungan hidup perusahaan dengan tidak hanya melakukan tugas formal saja (task performance) melainkan melakukan suatu pekerjaan yang lebih meskipun bukan tanggung jawab dan tugas utama dalam bekerja seperti membantu pekerjaan karyawan lainnya, menganggap perusahaan milik sendiri sehingga adanya keinginan untuk merawat dan

\footnotetext{
${ }^{1}$ Rion Nofrianda, Universitas Ahmad Dahlan, rionnofrianda@gmail.com

${ }^{2}$ Erita Yuliasesti Diah Sari, Universitas Ahmad Dahlan, erita.sari@psy.uad.ac.id

${ }^{3}$ Herlina Siwi Widiana, Universitas Ahmad Dahlan, herlina.widiana@psy.uad.ac.id
} 
menjaga aset perusahaan, menggunakan waktu kerja yang efektif, serta tingginya inisiatif dalam melakukan pekerjaan.

Perilaku-perilaku yang tumbuh dan terimplementasikan dalam diri pegawai ini merupakan kinerja diluar tugas (non task performance atau contextual performance). Perilaku kinerja kontekstual memiliki kontribusi positif dalam organisasi untuk meningkatkan lingkungan organisasi, sosial atau psikologis yang diperlukan dalam mencapai kinerja yang efektif dan efisien. Kinerja kontekstual merupakan aktivitas yang berkontribusi dalam mempertahankan organisasi, sosial dan lingkungan psikologis secara tidak formal diperlukan sebagai bagian dari pekerjaan (Borman \& Motowidlo, 1997). Lebih lanjut Borman \& Motowidlo (1997) menyebutkan bahwa kinerja kontekstual dibutuhkan untuk dapat memaksimalkan produktivitas kerja dan meningkatkan efektivitas dan efesiensi perusahaan. Borman dkk., (2001) menjelaskan aspek kinerja kontekstual 1) antusias, 2) sukarela, 3) bekerjasama, 4) mematuhi peraturan, 5) mendukung dan membela tujuan organisasi.

Pradhan (2016) menjelaskan peran penting komitmen afektif sebagai moderator salah satunya dalam membentuk kinerja kontekstual karyawan dalam bekerja di perusahaan. Terwujudnya kinerja kontekstual karyawan pada dasarnya memiliki komitmen afektif yang muncul dari karyawan. Seorang karyawan berkomitmen dan loyal akan berkontribusi lebih dari pekerjaan formal atau atau bekerja melebihi tugas utamanya. Pernyataan ini menguatkan dugaan bahwa untuk meningkatkan kinerja kontekstual karyawan, perlu adanya dorongan untuk memiliki komitmen afektif selain mendorong karyawan untuk menjalankan budaya kerja dan mencapai kepuasan kerja. Komitmen afektif selain berperan secara langsung terhadap kinerja kontekstual juga dapat berperan sebagai variabel moderator. Beberapa penelitian yang telah dilakukan membuktikan bahwa komitmen afektif mampu memediasi terbentuknya kinerja kontekstual pada karyawan. Komitmen afektif memiliki dampak terhadap keinginan karyawan untuk keluar dari organisasi (Delobbe dan Vanderghe (2004). Hal ini juga ditentukan oleh adanya komitmen afektif secara emosional kepada organisasi (Rhoades, Eisenberger \& Armeli, 2001). Becker (Allen \& Meyer, 1990) menyebutkan bahwa komitmen afektif merupakan sebuah kecenderungan bagi seseorang untuk memiliki keterikatan yang sangat kuat dengan organisasi. Allen \& Meyer (1990) menjelaskan aspek komitmen afektif yaitu keterikatan emosional, identifikasi dan partisipiasi.

Borman dkk, (2001) menyatakan faktor-faktor penyebab kinerja kontekstual, diantaranya dukungan interpersonal, dukungan organisasi dan inisiatif kesadaran. Faktor-faktor ini diindikasikan memengaruhi pegawai dalam memberikan kinerja optimal melalui perilaku untuk melakukan pekerjaan diluar peran mereka. Beberapa penelitian menyebutkan bahwa kinerja kontekstual dapat dipengaruhi budaya organisasi (Zhang, 2016; Govender, 2017). Budaya organisasi merupakan norma dan nilai yang berpengaruh terhadap perilaku dalam organisasi (Luthans, 2011) sehingga karyawan menyesuaikan perilakunya dengan budaya di organisasi untuk dapat diterima oleh lingkungan (Robbins, 2015). Penelitian Zhang (2016) menyebutkan bahwa terdapat tingkat rasio varian dengan jumlah $61 \%$ pengaruh dari budaya organisasi terhadap kinerja kontekstual.

Budaya organisasi bertujuan merubah sikap dan perilaku karyawan untuk dapat berkontribusi dalam produktivitas kerja sehingga dapat meningkatkan jiwa gotong royong, keterbukaan sesama karyawan, kebersamaan, serta komunikasi yang efektif merupakan unsur dalam kinerja kontekstual (Oemar, 2013). Aspek budaya organisasi menurut Robbins (2015) terdiri dari tujuh karakteristik yaitu; orientasi dan mengambil risiko, perhatian pada hal-hal rinci, orientasi pada hasil, orientasi pada manusia, orientasi pada tim, bersikap agresivitas dan stabilitas.

Kepuasan kerja merupakan salah satu faktor prediktor yang dapat mempengaruhi kinerja kontekstual (Edwards, 2008). Kepuasan kerja merupakan penilaian evaluatif tentang tingkat kesenangan karyawan berasal dari pekerjaan yang terdiri dari afektif dan komponen 
kognitif (Hulin \& Judge, 2003). Kepuasan kerja merupakan tanggapan atau penilaian karyawan terhadap organisasinya yang meliputi hubungan dengan atasan dan rekan kerja, karir maupun gaji (Pushpakumari, 2008). Spector (1985) menjabarkan sembilan indikator kepuasan kerja yaitu gaji, promosi, supervisi, benefit, pengakuan, peraturan, rekan kerja, tugas dan komunikasi.

Analisis empiris oleh Pushpakumari (2008) menyebutkan bahwa karyawan yang puas dengan pekerjaannya cenderung untuk memperpanjang masa kerja untuk mencapai prestasi kerja dan bekerja lebih baik serta lebih termotivasi. Temuan Pushpakumari didukung oleh penelitian Edwards, Bell, JR \& Decuir (2008) yang melakukan penelitian tentang hubungan antara kepuasan kerja dengan kinerja kontekstual. Penelitian dilakukan terhadap 444 responden karyawan pabrik di Texas Tenggara Amerika Serikat menyebutkan terdapat hubungan kepuasan kerja terhadap kinerja kontekstual. Kinerja kontekstual biasanya dikaitkan dengan apa yang "dikembalikan oleh karyawan" ke organisasi. Jika karyawan puas dengan pekerjaan, kemungkinan besar akan membalas dengan membantu orang lain serta melakukan tugas tambahan yang merupakan inti kinerja kontekstual. Kepuasan kerja secara keseluruhan memiliki hubungan yang kuat dengan kinerja kontekstual.

Berdasarkan pemaparan diatas, hipotesis dalam penelitian ini, yaitu;

1. Ada pengaruh budaya organisasi terhadap kinerja kontekstual.

2. Ada pengaruh kepuasan kerja terhadap kinerja kontekstual.

3. Ada pengaruh komitmen afektif terhadap kinerja kontekstual.

4. Ada pengaruh budaya organisasi terhadap kinerja kontekstual dengan komitmen afektif sebagai moderator.

5. Ada pengaruh kepuasan kerja terhadap kinerja kontekstual dengan komitmen afektif sebagai moderator.

Berdasarkan pemaparan tersebut dirumuskan tujuan penelitian ini untuk menguji pengaruh budaya organisasi dan kepuasan kerja terhadap kinerja kontekstual dengan komitmen afektif sebagai moderator.

\section{METODE PENELITIAN}

\section{Variabel Penelitian}

Adapun variabel penelitian yaitu kinerja kontekstual sebagai variabel endogen, variabel eksogen yaitu budaya organisasi dan kepuasan kerja, serta sebagai variabel moderator komitmen afektif.

\section{Subjek Penelitian}

Subjek penelitian terdiri dari 100 orang karyawan outlet rumah makan yang berstatus tetap pada tiga lokasi di area Kota Y.

\section{Metode Pengumpulan Data}

Variabel yang digunakan pada penelitian yaitu kepuasan kerja, budaya organisasi, komitmen afektif dan kinerja kontekstual. Pengukuran menggunakan beberapa skala yang telah diadaptasi dari penelitian sebelumnya. Skala untuk mengukur budaya organisasi diadaptasi dari Astuti (2019) dengan tingkat reliabilitas yaitu 0,947, skala kepuasan kerja diadaptasi dari Spector (1985) dengan tingkat reliabilitas tingkat reliabilitas 0,91, skala kinerja kontekstual diadaptasi dari Kany (2019) dengan koefisien reliabilitas alpha sebesar 0,0862 dan skala komitmen afektif diadaptasi dari Allen \& Meyer (1990) dengan empat respon pilihan yaitu STS (Sangat Tidak Sesuai), Tidak Sesuai (TS), Sesuai (S) dan SS (Sangat Sesuai) 
Penelitian ini menggunakan analisis data Partial Least Square-Structural Equation Modelling (PLS-SEM) yang merupakan sebuah teknik dalam statistik untuk melakukan uji terhadap model statistik dalam bentuk model-model sebab-akibat yang digunakan. SEM dapat mengkombinasikan secara kompleks analisis faktor dan regresi atau analisis jalur (Hox \& Bechger, 1999). Pemilihan PLS sebagai metode analisis adalah penelitian ini bersifat prediktif dan PLS memiliki tujuan untuk memprediksi dan data tidak harus berdistribusi normal, serta mampu menganalisis bentuk indikator baik reflektif maupun formatif (Ghozali, 2015).

\section{Teknik Analisis Data}

Analisis data dilakukan dengan model persamaan structural / SEM (Structural Equation Model) digunakan menggunakan program Smart Partial Least Square.

\section{HASIL DAN PEMBAHASAN}

Berdasarkan data tersebut dilakukan kategorisasi pada empat variabel penelitian menetapkan kriteria kategori dengan asumsi skor subjek dalam populasi terdistribusi berdasarkan kurva normal (Azwar, 2015). Berikut adalah kategorisas variabel penelitian:

Tabel 1. Kategorisasi KinerjaKontekstual

\begin{tabular}{cclccc}
\hline No. & Variabel & Kategori & Interval & Frekuensi & Persentase \\
\hline 1 & Kinerja Kontekstual & Tinggi & $X \geq 49$ & 50 & 50 \\
& & Sedang & $17-48$ & 50 & 50 \\
& & Rendah & $\leq 16$ & - & 0 \\
& & Total & & 100 & 100 \\
\hline 2. & Budaya Organisasi & Tinggi & $X \geq 72$ & 29 & 29 \\
& & Sedang & $19-71$ & 71 & 71 \\
& & Rendah & $\leq 18$ & - & 0 \\
& & Total & & 100 & 100 \\
\hline 3. & Kepuasan Kerja & Tinggi & $\mathrm{X} \geq 104$ & 76 & 76 \\
& & Sedang & $27-103$ & 24 & 24 \\
& & Rendah & $\leq 26$ & - & 0 \\
& & Total & & 100 & 100 \\
\hline 4. & \multirow{2}{*}{ Komitmen Afektif } & Tinggi & $\mathrm{X} \geq 25$ & 42 & 42 \\
& & Sedang & $9-24$ & 58 & 58 \\
& & Rendah & $\leq 8$ & - & 0 \\
& & Total & & 100 & 100 \\
\hline
\end{tabular}

Sumber: data primer (2019)

Berdasarkan tabel kategorisasi diatas pada masing-masing variabel penelitian diperoleh hasil bahwa pada variabel kinerja kontekstual, 50\% responden berada pada kategori tinggi dan $50 \%$ lainnya pada kategori sedang. Variabel budaya organisasi tersebut menunjukkan 29\% responden berada pada kategori tinggi dan $71 \%$ dalam kategori sedang. Kategorisasi variabel kepuasan kerja diperoleh hasil $76 \%$ responden berada pada kategori tinggi dan $24 \%$ dalam kategori sedang. Kategorisasi pada variabel komitmen afektif menunjukkan bahwa $42 \%$ responden berada pada kategori tinggi dan 58\% dalam kategori sedang. Pengujian hipotesis dalam penelitian ini menggunakan nilai statistik alpha 5\%, nilai t-statistik adalah 1.96 sehingga kriterian penerimaan atau penolakan hipotsa Ha diterima dan $\mathrm{H0}$ ditolak ketika skor t- statistik $>1.96$. Hipotesis ditolak atau diterima menggunakan probabilitas maka Ha diterima jika nilai $\mathrm{p}<0.005$ (Husein, 2015). 


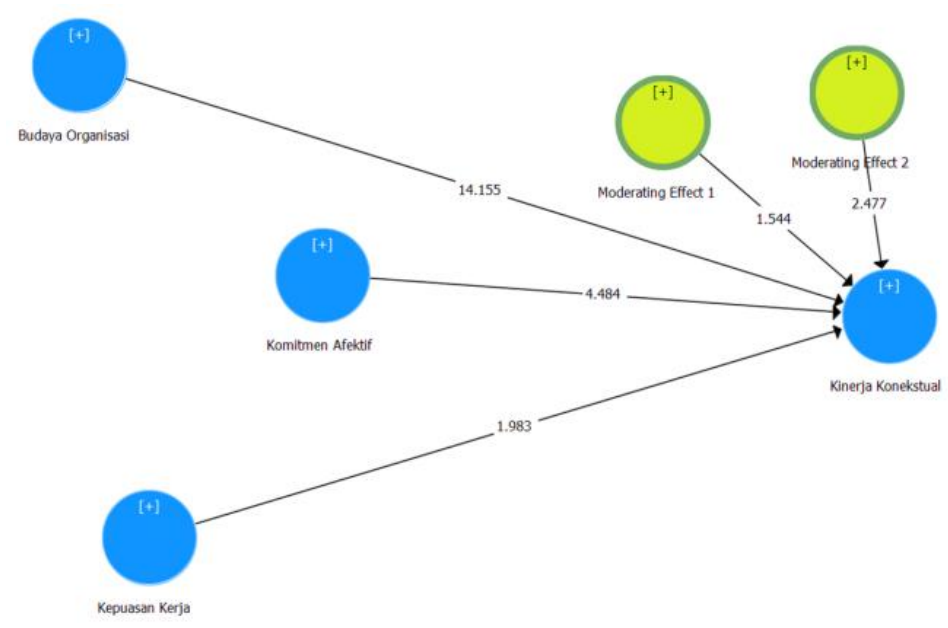

Gambar 1. Path diagram hasil analisis bootstrapping

Tabel 2. Hasil Analisis Jalur (Path Coefficient)

\begin{tabular}{lcccc}
\hline Model Pengaruh & $\begin{array}{c}\text { St.Dev. } \\
(\text { STDEV })\end{array}$ & t-statistic & $\begin{array}{c}p \text {-Values } \\
(<0.05)\end{array}$ & Hasil \\
\hline $\mathrm{BO} \rightarrow \mathrm{KK}$ & 0.102 & 14.155 & 0.000 & Signifikan \\
$\mathrm{K} \rightarrow \mathrm{KK}$ & 0.018 & 1.983 & 0.048 & Signifikan \\
$\mathrm{KA} \rightarrow \mathrm{KK}$ & 0.108 & 4.484 & 0.000 & Signifikan \\
\hline
\end{tabular}

Berdasarkan hasil uji hipotesis menunjukkan hubungan langsung antara variabel budaya organisasi dan kinerja kontekstual dinyatakan signifikan ( $\mathrm{t}$-statistik $>1.96$ dan $\mathrm{p}$-values $<0.05)$. Hasil ini dapat disimpulkan yaitu budaya organisasi berpengaruh langsung terhadap kinerja kontekstual. Ketika karyawan dalam organisasi mengimplementasikan budaya organisasi dalam bekerja maka akan mendorong perilaku kinerja kontekstual pada karyawan. Hal ini menandakan hipotesis pertama diterima. Zhang (2016) menyebutkan budaya organisasi berpengaruh signifikasi terhadap kinerja kontekstual. Hasil ini bertolak belakang dengan Ong Yu (2018) menyebutkan bahwa budaya organisasi tidak berdampak signifikasi terhadap kinerja kontekstual.

Pengaruh kepuasan kerja signifikan terhadap kinerja kontekstual (t-statistik> 1.96 dan p-values < 0.05), dapat disimpulkan bahwa kepuasan kerja karyawan berpengaruh langsung terhadap kinerja kontekstual. Ketika karyawan merasa puas dengan pekerjaannya maka akan mendorong perilaku kinerja kontekstual pada karyawan. Kappagoda (2012) menyebutkan bahwa kepuasan kerja memiliki pengaruh positif yang signifikan terhadap kinerja kontekstual. Hasil penelitian lain yang sejalan yaitu Edward, Bell, Arthur \& Decuir (2008) menyebutkan bahwa kepausan kerja berpengaruh terhadap kinerja kontekstual. Blau (dalam Edward, Bell, Arthur \& Decuir, 2008) menyatakan bahwa karyawan berusaha untuk menyeimbangkan antara yang diberikan dan diterima dari pertukaran sosial terutama terkait dengan target.

Pengaruh komitmen afektif terhadap kinerja kontekstual dinyatakan signifikan (tstatistic > 1.96 dan p-values < 0.05). Hal ini dapat disimpulkan bahwa komitmen afektif karyawan berpengaruh langsung terhadap kinerja kontekstual. Ketika karyawan memiliki komitmen afektif dengan organisasinya maka akan mendorong perilaku kinerja kontekstual pada karyawan, hal ini menandakan hipotesis ketiga diterima. Al-Zefeiti \& Mohamad (2017) menyebutkan komitmen afektif berpengaruh signifikan terhadap kinerja kontekstual. 
RION NOFRIANDA, ERITA YULIASESTI DIAH SARI \& HERLINA SIWI WIDIANA, Kinerja Kontekstual Dan Faktor-Faktor Yang Memengaruhi

\begin{tabular}{lcccc}
\multicolumn{5}{c}{ Tabel 3. Hasil analisis jalur (path coefficient) moderator } \\
\hline Model Pengaruh & $\begin{array}{c}\text { St.Dev. } \\
\text { (STDEV) }\end{array}$ & t-statistic & p-Values $(<0.05)$ & Hasil \\
\hline $\mathrm{KK} \leftarrow \mathrm{BO}+\mathrm{KA}$ & 0.012 & 1.544 & 0.123 & Tidak Signifikan \\
$\mathrm{KK} \leftarrow \mathrm{K}+\mathrm{KA}$ & 0.016 & 2.477 & 0.014 & Signifikan \\
\hline
\end{tabular}

Peran komitmen afektif sebagai moderator tidak terbukti mampu memoderisasi budaya organisasi dengan baik terhadap kinerja kontekstual, yang mana hasil dari pengolahan data menunjukkan t-statistik $1.54<\mathrm{t}$-tabel 1.96. Komitmen afektif tidak signifikan sebagai moderator antara budaya organisasi dan kinerja kontekstual. Hal ini menandakan hipotesis keempat ditolak.

Peran komitmen afektif sebagai moderator terbukti mampu memoderratori kepuasan kerja dengan baik terhadap kinerja kontekstual, yang mana hasil dari pengolahan data menunjukkan t-statistic $2.47>$ t-tabel 1.96. Komitmen afektif signifikan sebagai moderator antara kepuasan kerja dan kinerja kontekstual. Hal ini menandakan hipotesis kelima diterima.

\section{KESIMPULAN}

Berdasarkan hasil penelitian yang dilakukan dapat disimpulkan yaitu terdapat pengaruh positif yang signifikasi antara budaya organisasi dan kepuasan kerja terhadap kinerja kontekstual pada karyawan. Komitmen afektif juga berpengaruh signifikan terhadap kinerja kontekstual. Komitmen afektif tidak mampu memoderatori pada pengaruh budaya organisasi terhadap kinerja kontekstual, namun komitmen afektif secara signifikan mampu memoderatori pada pengaruh kepuasan kerja terhadap kinerja kontekstual. Peneliti selanjutnya dapat mengembangkan lebih lanjut dengan meneliti dan menganalisis pengaruh variabel lain selain dari penelitian ini untuk memiliki gambaran dan hasil yang berbeda pada variabel yang belum digunakan. Saran kepada organisasi yaitu agar lebih memperhatikan karyawan bukan hanya tugas formal namun memperhatikan kinerja kontekstual. Hal ini bertujuan untuk menciptakan dan meningkatkan lingkungan organisasi, sosial atau psikologis yang diperlukan dalam mencapai kinerja yang efektif dan efisien.

\section{DAFTAR PUSTAKA}

Al Zefeiti, S. M. B., Mohamad. M. A. (2017). The Influence of Organizational Commitment on Omani Public Employees' Work Performance. International Review of Management and Marketing, 7(2), 151-160.

Allen, N. J., \& Meyer, J. P. (1990). The measurement and antecedents of affective, continuance and normative commitment to the organization. Journal of occupational psychology, 63(1), 1-18.

Astuti, P., Sari, E. Y. D., \& Widiana, H. S. (2019). organizational citizenship behaviour (ocb) pada paramedis. Jurnal Psikologi Integratif, 7(1), 31-41.

Azwar, S. (2015). Penyusunan Skala Psikologi (Edisi 2). Yogyakarta: Pustaka Pelajar

Borman, W. C., \& Motowidlo, S. J. (2014). Organizational citizenship behavior and contextual performance: A special issue of human performance. Psychology Press.

Borman, W. C., Buck, D. E., Hanson, M. A., Motowidlo, S. J., Stark, S., \& Drasgow, F. (2001). An examination of the comparative reliability, validity, and accuracy of performance 
ratings made using computerized adaptive rating scales. Journal of Applied Psychology, 86(5), 965.

Delobbe, N., \& Vandenberghe, C. (2004). A four-aspekonal model of organizational commitment among belgian employees. European Journal of Psychological Assessment. 16(2), 125-138.

Edwards, B. D., Bell, S. T., Jr, W. A., \& Decuir, A. D. (2008). Relationships between facets of job satisfaction and task and contextual performance. Applied Psychology: An International Review, 57(3), 441-465 doi: 10.1111/j.1464-0597.2008.00328.x.

Folorunso, O.O., Adewale, A.J., Abodunde, S.M. (2014), Exploring the effect of organizational commitment dimensions on employees performance: An empirical evidence from Academic Staff of Oyo State Owned Tertiary Institutions, Nigeria. International Journal of Academic Research in Business and Social Sciences, 4(8), 275-286.

Ghozali, I., \& Latan, H. (2015). Partial Least Squares, konsep, teknik dan aplikasi menggunakan program Smartpls 3.0 untuk penelitian empiris. Semarang: Badan Penerbit UNDIP.

Govender, K. K. (2017). Leadership styles, organisation culture, and employee performance. International Review of Management and Marketing,7(4), 191-200.

Hox, J.J.\&Bechger, T.M. (1999). An Introduction to Structural Equation Modeling.Family Science Review. 11, 354-373.

Hulin, C. L., \& Judge, T. A. (2003). Job attitudes. dalam W. C. Borman, D. R. ligen, \& R. J. Klimoski (Eds.), Handbook of psychology: Industrial and organizational psychology. Hoboken, NJ: Wiley.

Kany, A. (2019). Pengaruh psychological capital dan perceived organizational support terhadap contextual performance dengan moderator spiritualitas kerja pada karyawan generasi millenial. (Tesis tidak dipublikasikan). Fakultas Psikologi Universitas Islam Negeri Syarif Hidayatullah, Jakarta.

Kappagoda, U. W. M. R. (2012, February). Job Satisfaction and Its Impact on Task and Contextual Performance in the Banking Sector in Sri Lanka. In Proceedings, 1st International Conference on Management and Economics.

Luthans, F. (2011). Organizational behavior (12th ed). An Evidence-Based Approach. New York: McGraw-Hill.

Motowidlo, S. J. (2000). Some basic issues related to contextual performance and organizational citizenship behavior in human resource management. Human Resource Management Review, 10(1), 115-126.

Niehoff, B, P., \& Moorman, R.H. (1993). Justice as a mediator of the relationship between methods of monitoring and organizational citizenship behavior. Academy of Management Jounal. 36(3), 327-556. 
Oemar, Y. (2013). Pengaruh budaya organisasi, kemampuan kerja, dan komitmen organisasi terhadap organizational citizenship behavior (OCB). JurnalAplikasi Manajemen, 11 (1),65 76 .

Ong Yu, V. S., \& Wang. Y. (2018). The influence of organization culture on middle-level managers' contextual performance with commitment as a mediating variable. Perspectives of Innovations, Economics \& Business, 18(2)

Yu, V. S. O., \& Wang, Y. (2018). the influence of organization culture on middle-level managers'contextual performance with commitment as a mediating variable. Perspectives of Innovations, Economics and Business, 18(2), 58-71.

Pradhan, S., Jena, L. K., \& Bhattacharyya, P. (2016). Transformational leadership and contextual performance: role of integrity among Indian it professionals. International journal of productivity and performance management. https://doi.org/10.1108/IJPPM08-2016-0186.

Pradhan, S., Jena, L. K., \& Bhattacharyya, P. (2018). Transformational leadership and contextual performance: Role of integrity among Indian IT professionals. International Journal of Productivity and Performance Management, 67(2), 445-462.

Pushpakumari, M. D. (2008, January). The impact of job satisfaction on job performance: An empirical analysis. In City Forum (Vol. 9, No. 1, pp. 89-105).

Rhoades, L., Eisenberger, R., \& Armeli, S. (2001). Affective commitment to the organization. the contribution of perceived organizational support. Journal of Applied Psychology, $86,(5), 825-836$.

Robbins, S., \& Judge, T. (2015). Organizational behavior. England: Pearson Education Limited.

Spector, P. E. (1985). Measurement of Human Service Staff Satisfaction: Development of the Job Satisfaction Survey. American Journal of Community Psychology, 13(6),693-713.

Zhang, W. J. (2016). Relationship between organizational culture identity and job performance of enterprise employees. DEStech Transactions on Social Science, Education and Human Science, (icaem). 